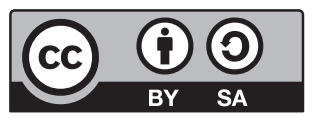

\title{
Dyslexia, Self-efficacy, and Language Instruction in Foreign Language Learning- A Mixed Quantitative-qualitative Study
}

\begin{abstract}
The aim of the research is to investigate the interdependence between dyslexia, selfefficacy, and foreign language instruction. The author of the study applied a mixed-method: quantitative and qualitative. The quantitative data were collected through self-efficacy questionnaires filled out by dyslexic and non-dyslexic students, and the qualitative data were collected during a case study conducted with a dyslexic student. The research findings in the first quantitative part of the study reveal that self-efficacy in dyslexic students is substantially lower than in non-dyslexic students. According to the results of the second mixed, quantitative-qualitative part of the study encompassing a case study, foreign language instruction has an impact on dyslexic students' self-efficacy and appropriate language instruction rises self-efficacy in students with dyslexia.
\end{abstract}

Keywords: dyslexia, self-efficacy, foreign language instruction, language learning, language teaching

\section{Dyslexia and Dyslexia Related Foreign Language Learning Problems}

In each school environment teachers deal with students of at least average intellectual level but displaying symptoms of learning difficulties, primarily in reading and writing. According to the data revealed by the Polish Dyslexia Association 10-15\% children worldwide are affected by dyslexia, 4\% by deep dyslexia. Based on various learning difficulties Bogdanowicz (1993) distinguished four dyslexia types: 
- visual dyslexia: learning problems cover mainly perception, aural memory combined with difficulties related to language function;

- integrative dyslexia: difficulties concerning motor skills-integration of perception;

- mixed dyslexia: difficulties related to aural perception and memory, visual memory of words, visual sequencing memory as well as spatial imagination;

- aural dyslexia: related to perception and auditory memory disorders frequently combined with language function disorder.

Dyslexic students experience educational difficulties not only learning their native language but also foreign language (Crombie, 2000; Kormos et al., 2009). These difficulties concern orthographic and phonological processing of sentences, reciting or weak utterance fluency; poor phonemic awareness characterized by lack of proper spelling which in turn results in problems with vocabulary learning due to poor working memory; lack of metacognitive abilities or individual language analysis, self-assessment or weak concentration.

Foreign language learning difficulty is determined by interdependence between graphic signs and sounds, which in science is called deep orthography (Frost, 2005). Deep orthographies can be characterized by inconsistent and unpredictable interdependence. English is a language with deep orthography in which this relationship is unstable, and the same graphic signs can be read in different letters in various ways which affects and increases learning difficulties (Spencer, 2007). Polish language, on the other hand, is a transparent language where graphic signs are always read in the same way. As a result, foreign language learning proves to be exceptionally difficult for students with dyslexia.

\section{Self-efficacy}

Affective factors have an impact on learners' foreign language success. According to some authors affectivity is even more important than students' aptitude (Chastain, 1988), and self-efficacy is believed to be crucial in academic performance.

Self-efficacy theory has been introduced by Albert Bandura (1977, 1997), who based his model on socio-cognitive theory according to which people are capable of undertaking the intentional activity. This activity is prioritized in accordance with trifold relations. It points out that individuals' acts have an impact on their future behavior being a result of trifold interrelated associations which cover: the environment in which individuals are brought up, their behavior, and biological factors. The trifold model determines people's opinions about themselves and affects their acts (Bandura, 1977). 
Albert Bandura came to the conclusion that people's opinions about their opportunities to act and the effects of their efforts have an impact on the way they behave. In his book Social Foundations of Thought and Action, Bandura claims that people's personal development is based on "what people think has an impact on their behaviour" (Bandura, 1983, p. 8).

Bandura (1977) in his cognitive theory enumerated the main sources of selfefficacy. Among them he listed: mastery experiences, modelling, verbal-social persuasion, and physiological and affective states. Mastery experiences are the most essential sources of self-efficacy and they relate to people's perception of their own previous success or failure. Thus, after the task is done by individuals, they assess the result of their effort. When they come to the conclusion that their effort led to success, self-efficacy when dealing with similar task, increases. Conversely, when they perceive their effort unsuccessful, they become unsecure during similar task.

Moreover, students built their self-efficacy through modelling, that is, observing the others and interpreting their experiences (Usher \& Pajeras, 2006). The more students identify themselves with role models, the more probably it is that their self-efficacy will increase (Bandura, 1986). For instance, when the learner gets 50 out of 100 points in the test and discovers that the other classmates obtained fewer points, it is likely that student's self-efficacy will increase. On the other hand, when the student learns that the other classmates received more points, the learner's self-efficacy will decrease.

The subsequent source of self-efficacy is the verbal-social persuasion of significant others. In verbal-social persuasion students' self-evaluation is realized based on students' assessment of significant others. The students' attitude towards those people depends on how they trust them and their professionalism. Moreover, Bandura (1986) underlined that verbal persuasion is more efficient when it causes a long-lasting increase in self-efficacy. Thus, it is advisable to find a person, role-model who is capable of doing the task sufficiently. It could be a teacher, a parent, or symbolic model such as a person known from media (Bandura, 1997). In foreign language learning self-efficacy relates to self-regulation noticeable in metacognitive strategies. Academic self-efficacy describes individuals' assurance in realizing educational activities on a given level (Shunk, 1991). Thus, learners with a higher level of aptitude are more successful learners than those with lower aptitude. However, academic performance is a process covering various factors so high aptitude does not determine success. 


\section{Multisensory Instruction}

Contemporary foreign language teaching theories suggest language learning which resembles native language learning: firstly, by listening, then speaking and reading, followed by writing. The widely employed teaching method is a communicative method in which meaning is inferred from the context, grammar rules are taught directly and the interdependence between a sound and a symbol has been limited (Ganschaw et al., 2000).

Nevertheless, researches confirm that the traditional teaching approach proves to be more efficient in teaching students with learning difficulties (Ganschaw et al., 1998). Reading comprehension with verbal processing combined with processing through recognition of words, symbol identification was efficient in teaching students with learning difficulties. Very important is early contact with orthography (relation between sound and its graphic sign) (Sparks et al., 2006).

Since the communicative method turned out to be inefficient in teaching dyslexic students, multisensory teaching instruction appeared the more effective method in teaching these students. In this method all senses are activated in accordance with the rule: seeing, hearing, and doing. It was presented for the first time by Gillingham and Stillman in 1960, and subsequently introduced in some schools around the world as a teaching method for dyslexic students. Teaching is realized with the employment of direct instruction, the meaning should not be inferred by students, but rather provided by a teacher. Dyslexics benefit primarily when they receive systematic and structured grammar and phonetic rules which are followed by relevant exercises and consolidation of knowledge they obtained.

Moreover, activation of various sensory channels is essential. Therefore, children make letter models from plasticine, trace words written on paper, carpet or sand. When their perception channel has been opened, they find the relationship between graphic and phonological aspects of words. As a result, information is acquired in complex activation of different senses.

In multisensory teaching, students learn vocabulary using pictures. They are asked to look at the picture with a written word, they say the word and then write. They also learn vocabulary at the board by repeating the word after the teacher, who then writes the word on the board. Finally, students repeat the word again and write in their notebooks. The teacher can also separate syllables and sounds in words (Sparks et al., 1991).

Grammar concepts are taught directly. For instance, the teacher can introduce color code according to which red color is used to match the subject, blue to match the object and yellow, the verb. When such code is 
used systematically, the learners will understand grammar better (Kormos \& Smith, 2012).

Communicative exercises can also be conducted with the employment of multisensory teaching. This activity begins with natural communication through listening and speaking. Nevertheless, students should activate more senses while learning. That is why they can be asked to prepare cards with personal pronouns $m y$, your, his, etc. Later they write a few sentences with these pronouns and finally the learners are paired and one student is asked to read the sentence with personal pronoun, and the other student choses the second card with matching picture and repeats the sentence (Sparks et al., 1991).

However, opponents of multisensory instruction claim that in this method it is impossible to develop metacognitive processes and it does not take into account various learning and cognitive skills (Wearmouth \& Reid, 2008).

\section{Empirical Research}

\section{Methodology}

This part of the paper outlines the empirical study. The primary objective of a study was to explore the relationship between self-efficacy and dyslexia, and the secondary objective, to investigate the impact of teaching methods on self-efficacy in dyslexic student.

Even though there are many studies concerning self-efficacy in a school context, only a few of them have been investigating the relationship between self-efficacy and foreign language learning. However, none of the researches examine self-efficacy in connection with teaching instruction employed in teaching students with dyslexia. Therefore, the author of the study formulated the following research questions:

RQ1: What is the relationship between self-efficacy and foreign language learning?

RQ2: How does foreign language learning instruction affect dyslexic students' self-efficacy?

The study's data collection method was a mixed study. The quantitative study relates to the objective analysis of the data achieved from self-efficacy questionnaires conducted among dyslexic and non-dyslexic primary school students. The qualitative method is realized in the form of a case study conducted with a dyslexic student. 


\section{Participants, the Instrument, and the Procedure}

The informants in the quantitative part of the study were 20 dyslexic and 50 non-dyslexic primary school students who attend a primary school in Lędziny, Poland. There were 22 non-dyslexic girls, 28 non-dyslexic boys, and 20 dyslexic boys. The average age of the students was 13. All students studied English as a part of their school curriculum and had three hours a week of English class. As a result, they had at least 6-year English exposure at school.

In the first part of the study conducted with the application of the quantitative method, the employed instrument was a questionnaire consisting of 15 questions and distributed among the participants. Prepared by the researcher the Foreign Language Self-efficacy questionnaire measured the level of English language learning related self-efficacy. The researcher applied a scale evaluated according to a 4-point Likert scale ranging from 1 to 5 with the possible responses: strongly disagree -1 , disagree -2 , agree -3 , and strongly agree -4 , where 1 indicted very low, and 4 -very high self-efficacy. The data were collected within two weeks. The headteacher's permission to conduct research was obtained in the primary school.

The second part covered the qualitative case study without generalizing to the whole population, combined with the quantitative one. The participant of a qualitative case study was a 13-year-old boy with dyslexia who is a sixthyear student of a primary school in Mysłowice. The qualitative study helped to understand the situation which is unique, and has not been analyzed before. The case study lasted six weeks during which the researcher conducted six 45-minute classes with the student. Also, the researcher applied Foreign Language Self-Efficacy questionnaire, the same which was filled out by 70 primary school students. The questionnaire was employed to a dyslexic student before and after a case study.

\section{Research Results}

In the first part of the study the author attempted to answer the first research question. Hence, the quantitative methodology was applied. The data were collected within one week and was computed by means of the statistical software RStudio with the primary calculations being descriptive statistics: mean (M), and standard deviation (SD), as well as interferential statistics operations: The Mann Whitney Test, and the Shapiro-Wilk T-parametric Test conducted in order to investigate whether there was a statistical difference between self-efficacy means scores in dyslexic and non-dyslexic students. 
Table 1

Research results obtained from dyslexic and non-dyslexic students' self-efficacy foreign language questionnaires

\begin{tabular}{lllll} 
Variable & $\begin{array}{l}\text { All } \\
(70)\end{array}$ & $\begin{array}{l}\text { Non-dyslexics } \\
(50)\end{array}$ & $\begin{array}{l}\text { Dyslexics } \\
(20)\end{array}$ & $\begin{array}{l}\text { Dyslexics and } \\
\text { non-dyslexics }\end{array}$ \\
\hline & M SD & M SD & M SD & P-value T-value \\
\hline Self-efficacy & 39.846 .13 & 41.805 .59 & 34.954 .53 & $3.466 e-06-5.32461$
\end{tabular}

The research results reveal that there is a substantial difference in dyslexic and non-dyslexic learners of English with dyslexics experiencing lower levels of self-efficacy (M 34.95), than non-dyslexic students (M 41.80). Furthermore, the score of 6.13 obtained from SD calculation in all (dyslexic and non-dyslexic students) revealed a normal distribution of scores in all students where students' lowest score was 28 points in the Self-efficacy Foreign Language questionnaire, and the highest was 53 points in non-dyslexic students. The highest score which could have been obtained by the participants was 60 points, and the lowest -15 . The result 5.59 achieved from non-dyslexic students' questionnaires also show normal distribution of scores with the lowest score amounted 30 points and the highest - 53. Nevertheless, dyslexic students with a score 4.53 , displayed non-normal distribution, and their lowest score in the questionnaires was 28 , and the highest 45.

Following the procedure, as the sample size is not large, in order to compare the two groups of participants (dyslexics and non-dyslexics), the researcher applied The Mann Whitney interferential (Willcoxon Rank-sum Test). It is a non-parametric test which tests whether there is a significant difference in the two groups of participants. The value above 0.05 shows that there is no statistical difference. In this study, the P-value which amounted 3.466e-06 indicates that there is a substantial difference in self-efficacy between dyslexic and non-dyslexic students. Finally, in order to examine the result obtained from the Willcoxon Rank the researcher applied the Shapiro-Wilk t-parametric Test. The score -5.32461 confirmed the result achieved in the Willcoxon Rank-sum.

In order to answer the second research question, the author of the study administered a mixed quantitative-qualitative study. The participant of a qualitative study was a 13-year old dyslexic boy who holds an opinion from pedagogical-psychological suspensory. In the statement it has been stipulated that the boy has got decreased aural-vision-kinaesthetic integration as well as graphomotor abilities. In writing the boy commits many orthographic mistakes and distorts longer words. The boy reads slowly word by word. Moreover, his aural and phonological memory is limited, which results in weaker auditory channels. 
To see the whole picture of the conundrum, the author began the research with the Foreign Language Self-efficacy questionnaire filled out by a student. The mean was 2.3 which clearly indicates that the boy had low self-efficacy regarding foreign language learning. For instance, to the statement "English is one of the easiest subjects," he responded "strongly disagree." He also gave the same answer to another statement "Teachers take care of everything to ease me to understand what they explain." Moreover, the learner assessed himself as a weak English language student.

The case study was performed by the researcher, who is simultaneously an active English teacher and was conducted from 9 November until 20 December 2019. For the purpose of the study the researcher changed the boy's name into Adam. Adam is the student in a state primary school in Mysłowice. The author decided to work with Adam to examine what can be done to help a dyslexic student in foreign language learning. The study was based on the learner's student book Flash 6 (2019).

The first week. The author began the study examining the student's English language skills. Thus, she tested Adam's speaking, writing, listening, and reading skills. Adam did the language tasks as well as he could. At first, he seemed to be reluctant so as "an ice breaker" she applied Taboo game. In the game, the student had to describe the words he saw on the card without using enumerated words. Subsequently, the researcher checked Adam's writing skills to which she used vocabulary from student's book Flash. To encourage Adam to work, for listening the researcher selected a video from YouTube entitled "What are computers for kids. Intro to computers."

After the first session with Adam, it has been noticeable that the learner who is willing to communicate in English, struggles while speaking making a number of language mistakes. Moreover, he commits many grammar mistakes and pronounces incorrectly most of the English words. Regarding writing, Adam wrote correctly 4 words out of 20 . However, mistakes in his writing were not substantial for instance, instead of "ear infection," he wrote "er infection," or instead of "stomach ache," he wrote "stomachkage" and Adam's handwriting was illegible. While testing listening skill Adam watched the video with interest. However, it was problematic for Adam to report what he heard, either in Polish or in English. The last examined skill was reading the text Escape room from Adam's student's book. During reading Adam mispronounced many words or skipped some lines. Hence, initial diagnosis revealed the necessity of working on all the language skills.

The second week. During the second session the study was based on the fourth chapter In the News from Adam's student's book. The researcher focused on learning the vocabulary from the introduction to the chapter. She prepared flashcards with words such as "customer" or "virtual reality." Firstly, the tutor gave Adam flashcards with Polish and English meanings and his task was to 
join the meanings in both languages. Then she read the words in English and the student repeated after her. The next stage was to tell words in English. Finally, the student traced the words in English on the sand, and the last task was to say and write words in a notebook. Towards the end, to make the session more attractive the researcher asked Adam to draw eight words and to make a story with these words.

The training based on multisensory instruction, activating various perception channels proved to be successful. Adam was able to recall from his memory 18 out of 20 learned words. The task in which Adam was asked to make a story was done with enthusiasm. As Adam is interested in history, he created the story set during World War II. His story was incorrect and while creating it Adam asked about a few words but the aim of this part was rather to convince him that he can break the language barrier.

The third week. In the third session the researcher, following what student's book suggested focused on grammar, that is teaching modal verbs such as can, can't, could, couldn't, must, mustn't, have to, should, shouldn't. Firstly, the author of the study explained to Adam the usage of modal verbs referring to learner's experiences, for instance, "when you want to go out with your friends to play football you ask 'Can I go to the football pitch?"' The next step was to teach Adam how to use modal verbs. Here, the researcher used earlier prepared cards where the person, modal verb, and object were written in different colors. With these cards Adam learnt how to build affirmative sentences, questions, and negations. In the last task, the student did the exercises from his book.

Learning grammar with the reference to the boy's personal experiences helped him to understand the usage of modal verbs easier. The boy enjoyed learning grammar through cards, and later examination of acquired skills showed that the boy understood the topic and was able to build sentences with modal verbs himself. The only tasks which were done incorrectly were the ones where Adam did not understand the meaning of sentences.

Fourth week. This time the teacher focused on teaching reading comprehension. Adam worked with a text Droids at work from his student's book. Initially, Adam had to underline words he perceived difficult. Then, the trainer taught him these words and a few others with the multisensory method used earlier. The next point of the session was "shared reading" (Cimermanova, 2015) in which at first the researcher and then the student together with the teacher read the text in turns. Adam received a bookmark from the researcher, thanks to which he did not skip the lines. Subsequently, when it proved to be impossible for Adam to answer the questions to the text, they translated it together into a student's mother tongue. The following activity was to create his own comic with the words learnt during the session in which the webpage www. storyboardthat.com was valuable. 
Fifth week. This class involved listening comprehension. The text Internet safety tips served as a basis. In order to rise student's interest, the researcher prepared cards with vocabulary from the listening that is shopping online, logging in, antivirus software, and a stranger in the Internet. Firstly, the teacher and the student discussed the problems from the cards, and then Adam listened to the recording with the book closed. Finally, the boy did the task in which he filled in the gaps in the sentences placed under the text. Adam did not manage to do the whole exercise, thus he listened to the recording again to finish the task. Subsequently, the researcher focused on vocabulary which she taught Adam with cards and educational sand, after which the boy wrote the words in his notebook. The last, final stage of the fifth session was to check whether the student learnt the vocabulary doing a quiz prepared by the teacher with the assistance of the web application www.classtime.com.

Sixth week. The aim of the last session was to examine the effectiveness of earlier applied strategies and whether these methods had a considerable impact on Adam's self-efficacy. To achieve this goal the researcher examined all taught skills. She began with speaking in which the student participated in the conversation about his family, interests, and friends. These were not the topics discussed earlier. However, the teacher noticed that although Adam still made grammar and lexical mistakes, he willingly took part in the speaking practice. Then the researcher suggested the so-called controlled conversation that is based on one of the topics discussed during the sessions. This time, Adam had to select cards with vocabulary related to the text Internet safety, then he discussed the topics suggested in the cards. The following task was to write ten words which Adam had learnt during our case study and the learner wrote correctly six out of ten. Compared to the knowledge of vocabulary learnt before our sessions it was a good result. Subsequently, Adam read loudly the text he had never read before. The first thing he did was to reach for a bookmark which helped him read without skipping lines. He still made a lot of mistakes but he tried to read slowly and carefully. However, the last grammar task examined whether Adam was able to learn how to use modal verbs proved successful. Although the session related to modal verbs took place a few weeks before, the exercises were done perfectly with only a few mistakes.

In the last stage of the study Adam filled out the self-efficacy questionnaire, the same which he received before the case study. This time the average score was higher and it amounted for 2.9 which showed that after 6-week sessions with the trainer the boy's self-efficacy increased and he began to believe that he could make decisions related to foreign language learning independently. For instance, to the statement "I could get better grades if I worked more," he responded "yes," and not "no" like before the case study. 
Likewise, he agreed with the statement "Teachers care for us to understand everything."

\section{Discussion and Conclusion}

The presented study aimed to answer two research questions. The objective of the first research question was to examine foreign language self-efficacy in dyslexic and non-dyslexic students. Not surprisingly, the research results show that dyslexic students display a significantly lower levels of English language self-efficacy. The study results confirm the findings obtained from the research conducted by Stagg and Eaton (2018) who investigated self-efficacy in dyslexic, and non-dyslexic university students. Nevertheless, according to the researcher's knowledge, the present study is the first one investigating dyslexia, self-efficacy, and foreign language instruction.

The second research question examined the relationship between selfefficacy and English language learning in the dyslexic student. The results received from the Foreign Language Self-efficacy questionnaires filled out by a participant in a case study reveal that the employment of multisensory instruction improved his English learning related self-efficacy. It increased from 2.3 to 2.9. The lowest score which could have been obtained was 1 , and the highest -4 .

Summing up, 6-week time spent with Adam, the boy primarily needed serious support in order to help him to believe that he is capable of achieving success in foreign language learning. Observing Adam's engagement, it can be concluded that he needed the teacher's attention, and positive relation with the trainer encouraged him to work. Each session began with small talk and the teacher complemented each student's success. Regaining self-confidence in dyslexic student is perceived as an essential factor conditioning the skill to read and write (Nijakowska, 2010).

The participant benefited from multisensory instruction based on the simultaneous activation of a few senses while doing the task, which eased him to learn vocabulary and understand grammar, primarily creating the relationship between visual and phonological aspects of words. The employment of modern technologies: applications for creating comic books and a website for preparing quizzes was beneficial and motivating in boosting participant's confidence. Individual approach during private sessions caused that the boy began to believe in his language capabilities which lifted his self-efficacy, in dyslexic students usually lower than in students without any special educational needs (Stagg \& Eaton, 2018). 
There is a wide range of pedagogical implications of the present study. Research findings indicate that it is relevant to introduce special educational accommodations in public schools in order to ensure dyslexia-friendly education. More individualized approach should be realized in the form of special correction-compensation classes conducted with the application of the method adopted for teaching dyslexics during which students with special educational needs will receive positive feedback and support. Also, forgoing study shows that the application of multisensory instruction combined with modern technologies can be beneficial.

However, the attempt to generalize the following study results to the whole population can be a subject of certain limitations. The participants of the study filled out the questionnaires without the presence of the researcher which resulted in a lack of control over the procedure of data collection in the quantitative part of the research. Moreover, qualitative data were analyzed solely by the author. In order to avoid bias, another independent researcher with the same qualifications is recommended. The number of participants can also be inadequate. The quantitative study was conducted on 20 dyslexic and 50 non-dyslexic students. Thus, the research findings can be considered as assumptions rather than the facts relevant to the majority of Polish students.

\section{References}

Bandura, A. (1977). Social learning theory. Prentice Hall, Inc.

Bandura, A. (1983). Self-efficacy determinants of anticipated fears and calamities. Journal of Personality and Social Psychology, 45, 464-469.

Bandura, A. (1986). Social foundations of thought and action: A social-cognitive theory. Prentice-Hall, Inc.

Bandura, A. (1997). Self-efficacy: The exercise of control. Freeman.

Bogdanowicz, M. (1993). Specyficzne trudności w opanowaniu mowy pisanej: czytania i pisania [Specific Writing and Reading Difficulties]. In T. Gałkowski, Z. Tarkowski, \& Z. Zaleski (Eds.), Diagnoza i terapia zaburzeń mowy [Diagnosis and Therapy of Speech Impairment], (pp. 203-229). UMCS.

Chastain, K. (1988). Developing second language skills: Theory and practice (3rd ed.). Harcourt Brace Jovanovich.

Cimermanova, I. (2015). Teaching foreign languages to learners with special educational needs: E-textbooks for foreign language teachers. Constantine The Philosopher University.

Crombie, M. A. (2000). Dyslexia and learning of a foreign language at school: Where are we going? Dyslexia 6, 112-123.

Dooley, J. (2019). Flash. Student's book. Express Publishing. 
Frost, R. (2005). Orthographic systems and skills word recognition in reading. In M. J. Snowling \& C. Hulme (Eds.), The science of reading. A handbook (pp. 272-295). Blackwell.

Ganschow, L., \& Sparks, R. L. (2000). Reflection on language study for students with language learning problems: Research, issues and challenges. Dyslexia, 6, 87-100.

Ganschow, L., Sparks, R. L., \& Javorsky, J. (1998). Foreign language learning difficulties: A historical perspective. Journal of Learning Disabilities, 31(3), 248-258.

Gillingham, A., \& Stillman, B. W. (1960). Remedial training for children with specific disability in reading, spelling and penmanship (7th ed.). Educators Publishing Service.

Kormos, J., Sarkardi, A., \& Csizer, K. (2009). The language learning experiences of students with dyslexia: Lessons from an interview study. Innovation in Language Learning and Teaching, 3(2), 115-130.

Kormos, J., \& Smith, A. M. (2012). Teaching languages to students with specific learning difficulties. Multilingual Matters [Book review], CEPS Journal, 2, 181-183.

Nijakowska, J. (2010). Dyslexia in foreign language classroom. Multilingual Matters.

Sparks, R., Patton, J., Ganschow, L., Humbach, N., \& Javorsky, J. (2006). Native language predictors of foreign language proficiency and foreign language aptitude. Annals of Dyslexia, $56,129-160$.

Spencer, K. (2007). Predicting children's word-spelling difficulty for common English words from measures of orthographic transparency phonemic and graphemic length and word frequency. British Journal of Psychology, 98, 305-338.

Shunk, D. H. (1991). Self-efficacy and academic motivation. Educational Psychologist, 26 (3-4), 207-231.

Sparks, R., Ganschow, L., Kenneweg, S., \& Miller, K. (1991). Orthon Gillinham approach to teach a foreign language to dyslexic/learning disabled students: Explicit teaching of phonology in a second language. Annals of Dyslexia, 45, 187-214.

Stagg, S. D., \& Eaton, E. (2018). Self-efficacy in undergraduate students with dyslexia: A mixed methods investigation. British Journal of Special Education, 45(2), 1-29.

Usher, E. L., \& Pajeras, F. (2006). Sources of academic and self-regulatory efficacy beliefs of entering middle school students. Contemporary Educational Psychology, 31(2), 125-141.

Wermouth, J. P., \& Reid, G. (2008). Ocena i planowanie nauczania oraz nauki. [Assessment and Planning of Teaching and Learning]. In G. Reid \& J. Wermouth (Eds.), Dysleksja. Teoria I praktyka [Dyslexia. Theory and Practice] (pp. 211-234). Gdańskie Wydawnictwo Psychologiczne.

Bogusława Maria Gosiewska-Turek

\section{Legasthenie, Selbstwirksamkeit und Sprachunterricht beim Fremdsprachenlernen - eine gemischte quantitativ-quantitative Studie}

\section{Zusammenfassung}

Das Ziel der Arbeit ist es, die Wechselbeziehung zwischen Legasthenie, Selbstwirksamkeit und Fremdsprachenunterricht zu untersuchen. Die Autorin der Studie wandte eine gemischte (quantitative und qualitative) Methode an. Die quantitativen Daten wurden anhand der von 
legasthenen und nicht legasthenen Studenten ausgefüllten Fragebögen zur Selbstwirksamkeit erhoben und die qualitativen Daten - im Rahmen einer Fallstudie mit einem legasthenen Studenten. Die Forschungsergebnisse im ersten quantitativen Teil der Studie zeigen, dass die Selbstwirksamkeit bei legasthenen Studenten wesentlich geringer sei als bei nicht legasthenen Studenten. Laut Ergebnissen des zweiten gemischten (quantitativ-qualitativen) Teils, der eine Fallstudie umfasste, habe der Fremdsprachenunterricht einen Einfluss auf die Selbstwirksamkeit legasthener Studenten und der entsprechende Sprachunterricht erhöhe die Selbstwirksamkeit von Studenten mit Legasthenie.

Schlüsselwörter: Legasthenie, Selbstwirksamkeit, Fremdsprachenunterricht, Fremdsprachenlernen, Fremdsprachenlehren 